\title{
Malabsorption Syndrome Due to Tropheryma Whipplei Severe Infection in a Patient Thirteen Years after Kidney Transplantation

\author{
Abdellaoui $I^{1^{*}}$, Sahtout $\mathbf{W}^{1}$, Ben Mansour $\mathrm{I}^{2}$, Mokni $\mathbf{M}^{3}$, Azzabi $\mathbf{A}^{1}$, Mrabet $\mathbf{S}^{1}$, Guedri $\mathbf{Y}^{1}$, Zellama $\mathbf{D}^{1}$, Toumi $\mathbf{S}^{1}$, Sabri $^{1}$, Amor $^{1}$, Achour $^{1}{ }^{1}$ and Jmaa $\mathbf{A}^{2}$ \\ ${ }^{1}$ Nephrology, dialysis and transplantation ward, Sahloul hospital, France \\ ${ }^{2}$ Gastrology ward, Sahloul hospital, France
} \\ ${ }^{3}$ Pathology laboratory, Farhat Hached hospital, France
}

"Corresponding author: Abdellaoui I, Nephrology, dialysis and transplantation ward, Sahloul hospital, 33 Fourat street, Jawhara city, France, Tel: 0021655635905; Email: i.men.ab87@gmail.com

Received date: October 26, 2016; Accepted date: November 22, 2016; Published date: November 28, 2016

Copyright: ( 2016 Abdellaoui I, et al. This is an open-access article distributed under the terms of the Creative Commons Attribution License, which permits unrestricted use, distribution, and reproduction in any medium, provided the original author and source are credited.

\begin{abstract}
Whipple's disease (WD) is a rare chronic and multi-systemic infectious illness. The exposing factor to WD is an underlying genetic predisposition that leads to colonization of $T$. whipplei throughout the intestinal tract. Here, we report the first case of WD, to our knowledge, with typical systemic and gastrointestinal manifestations, malabsorption syndrome and serious alteration leading to death in a kidney transplant recipient. We intend to describe its clinical presentation, the methods for its diagnosis, and the outcome of treatment. It's a 27-year-old man without history of arthritis or diarrheal illness. He received a cadaveric graft in 23/12/1999 at the age of fifteen. His HLA analysis was A1 A33 B14 B35 BRB1*01 DRB1*11. The recipient lived in an urban environment without well water or animals. Five years after transplantation, he complained of diarrhoea and fever with a negative infectious work up. These gastrointestinal symptoms were resolved after empiric antibiotics. The recipient was hospitalized in 2012, thirteen years after transplantation, to explore a second episode of chronic afebrile diarrhoea with loss of weight and worsening of the graft function. Labs showed malabsorption syndrome, anaemia and leukopenia but no inflammatory signs. Anti-gliadine and anti-transglutaminase antibodies were negative. Bacteriological and parasitological stools tests as well as blood cultures were negative. Cytomegalovirus antigenemia and tumor markers were also negative. The patient has not been treated with antibiotics for WD and MMF toxicity was more likely to be responsible of the malabsorption syndrome. The mycophenolate mofetil was switched to Azathioprine. In October 2015, he was hospitalized for fever, diarrhoea and arthralgia without arthritis, hypokalemia, dehydration, important loss of weight and worsening of the graft function. The endoscopic exploration showed erythematous antral mucosa, severe gastritis and duodenal lymphangiectasia. Biopsies showed atrophied villi, abraded epithelium and filled villi axis with foamy macrophages strongly stained in PAS coloration. This histologic aspect is typically suggestive of $T$. whipplei intestinal infection. Sixteen years after transplantation, the patient was dead after two days in the intensive care unit. The diagnosis of WD was certain based on clinical and histopathological proofs.
\end{abstract}

Keywords: Whipple disease; Malabsorption syndrome; Kidney transplant; Infectious disease; Immunosuppressive therapy

\section{Introduction}

Whipple's disease (WD) is a rare chronic and multisystemic infectious illness. WD was first described in 1907 then the Tropheryma whipplei, a gram positive intracellular bacillus of the phylum actinobacteria, was successfully cultured in 2000 [1-3]. T. whipplei is a ubiquitous microorganism, and it has been suggested that it might be acquired through fecal-oral transmission [4]. There have only been about 1000 cases of this clinical disease in humans, with the majority of cases occurring in middle-aged white men [2].

The exposing factor to WD is an underlying genetic predisposition that leads to colonization of $T$. whipplei throughout the intestinal tract, lymphoreticular system, and central nervous system.

It is unclear why some individuals develop infection and others do not. Analysis of T. Whipplei genotypes has found no association with disease development suggesting that other factors including immunosuppressive therapy, acquired and genetic immunological defects, and comorbid disease may play a role in disease development $[2,5]$.

WD mainly involves the gastrointestinal tract, joints and central nervous system, but may also affect heart, liver, bone marrow, lungs, lymph nodes and skin [6]. Massive infiltration of affected tissues by macrophages staining positive for periodic acid Schiff (PAS) is the histopathological hallmark of WD [2].

The diagnosis of WD is suggested by duodenal biopsy when histology shows periodic acid-Schiff (PAS)-positive foamy macrophages, and can be confirmed by $T$. Whipplei directed polymerase chain reaction (PCR) [7]. WD is potentially easily treatable, the most widely antibiotic regimen being used is a 2 week initial course of ceftriaxone, followed by oral cotrimoxazole for 12-18 months [8].

According to the proposed physiopathological factors, a higher rate of WD should be anticipated in immunocompromised individuals. Surprisingly, only 4 previous cases of WD have been diagnosed after solid organ transplantation and none after hematopoietic cell transplantation $[5,9,10]$. 
In this report, we present a case of a Whipple's Disease diagnosed in a thirty years old patient thirteen years after cadaveric kidney transplantation. Here, we report the first case of WD, to our knowledge, with typical systemic and gastrointestinal manifestations, malabsorption syndrome and serious alteration leading to death in a kidney transplant recipient. We intend to describe its clinical presentation, the methods for its diagnosis, and the outcome of treatment.

\section{Case Report}

We report a 27-year-old man without history of arthritis or diarrheal illness. He was operated for renal lithiasis and pyelonephritis due to congenital malformation (no reflux uropathy, No primary hyperoxalemia) at an early age of 2 years (pyelotomy of the left kidney and nephrectomy of the right one). He reached the end-stage kidney disease (ESKD) at the age of eleven. He underwent peritoneal dialysis for 4 years.

Then after one episode of peritonitis due to staphylococcus epidermidis, he received a cadaveric graft in 23/12/1999 at the age of fifteen. His HLA analysis was A1 A33 B14 B35 BRB1*01 DRB1 ${ }^{*} 11$. Immunosuppressive induction drugs used were methylprednisolone and rabbit anti-thymocyte globulin (r-ATG) then he was transitioned to Cyclosporine A (Equoral 50mg-0-75mg per day) + mycophenolate mofetil (Cellcept 1,5g per day) + Corticosteroids for maintenance therapy. The recipient lived in an urban environment without well water or animals.

Between 2000 and 2004, his course was complicated by a repetitive urinary tract infection by pseudomonas Aeruginosa three times in a year. Explorations showed a neurological bladder and post-void residual urine and self-catheterization was indicated. Five years after transplantation, he complained of diarrhea and fever with a negative infectious work up. These gastrointestinal symptoms were resolved after empiric antibiotics.

In 2008, the patient was hospitalized for worsening of the graft function associated to urinary tract infection. But during that hospitalization, he had clinical and biological signs of Cyclosporine toxicity. So, he was switched to Sirolimus (Rapamune $2 \mathrm{mg}$ per day). No gastrointestinal troubles, arthralgia, arthritis or other orientation to WD was noted in that period.

The recipient was hospitalized in 2012, thirteen years after transplantation, to explore a second episode of chronic afebrile diarrhea with loss of weight and worsening of the graft function. Labs showed malabsorption syndrome, anemia and leucopenia but no inflammatory signs. Anti-gliadine and anti-transglutaminase antintibodies were negative. Bacteriological and parasitological stools tests as well as blood cultures were negative. Cytomegalovirus antigenemia and Tumor markers were also negative. The digital rectal examination was without any abnormalities. Subsequent endoscopic evaluation revealed partially scarcity in the duodenal folds, a normal macroscopic aspect of gastric and sigmoid mucosa. The colposcopy couldn't be conclusive because of technical problems. But the aspect of the colon mucosa explored to the right angle was normal. Also a sliding hiatus hernia was noted. The intestinal scan performed with iodine contrast showed hypotonic and dilated intestines, scarcity in the intestinal villi, no thickening in the last intestine wall and multiple mesenteric lymphadenopathies without any peritoneal effusion. That aspect suggests a Malabsorption syndrome without specific signs. Biopsies were performed but the results were not conclusive.
The patient has not been treated with antibiotics for WD and MMF toxicity was more likely to be responsible of the malabsorption syndrome. The mycophenolate mofetil was switched to Azathioprine (Imurel $100 \mathrm{mg}$ then tapered to $50 \mathrm{mg}$ ). In the regular controls of the patient, a progressive decrease of chronic diarrhea episodes but no complete disappearance was noted.

In October 2015, he was hospitalized for fever, diarrhea and arthralgia without arthritis, hypokalemia, dehydration, important loss of weight and worsening of the graft function. The morphology ultrasound and vascular Doppler examination were normal. Labs showed a creatinine rate at $550 \mathrm{umol} / \mathrm{l}$ and potassium at $2 \mathrm{mmol} / \mathrm{l}$, albumin rate at $30 \mathrm{~g} / \mathrm{l}$ and no inflammatory biological signs (normal count of white blood cells and normal CRP). The antibiotic empiric treatment was started: cefotaxim and metronidazole. The endoscopic exploration showed the same aspect of hiatus hernia, erythematous antral mucosa, severe gastritis and duodenal lymphangiectasia.

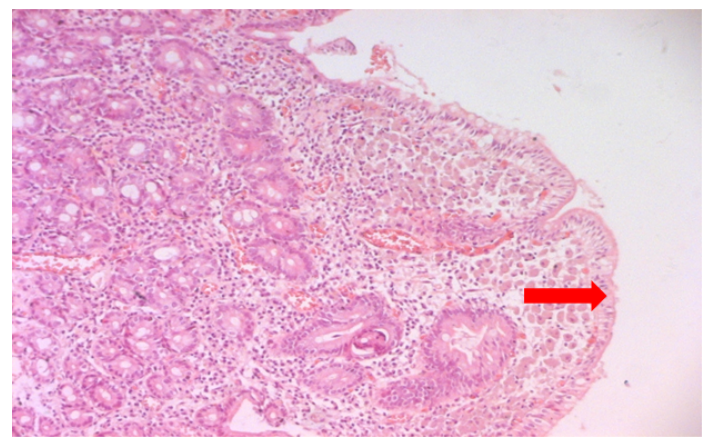

Figure 1: Duodenal mucosa with atrophied villi and chorionic infiltration by macrophages (HE X 100).

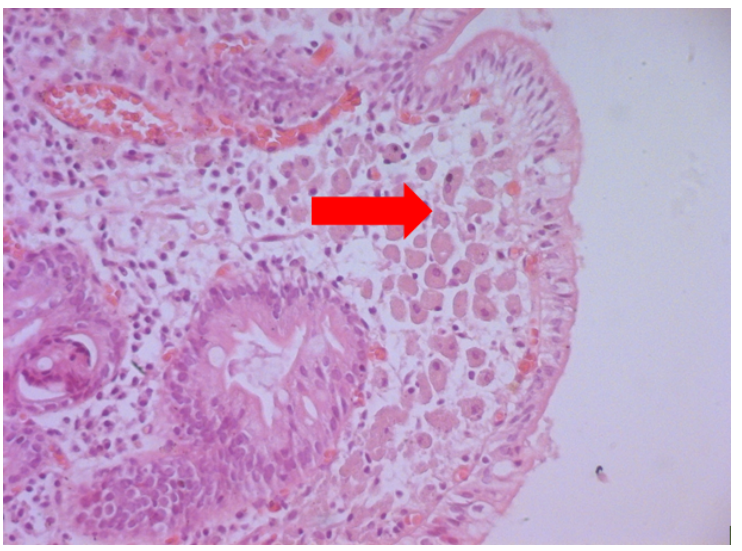

Figure 2: Duodenal mucosa with atrophied villi and chorionic infiltration by macrophages (HE X 200).

Biopsies showed atrophied villi, the epithelium is abraded; villi axis is filled with foamy macrophages strongly stained in PAS coloration. An inflammatory various cells infiltration is noted. But unfortunately no gram positive stained organism was seen nor any type of other parasite. This histologic aspect is typically suggestive of $T$. Whipplei intestinal infection (figure 1). 
Sixteen years after transplantation, the patient was deceased after two days in the intensive care unit (ICU) from a heart arrest due to arrhythmia. It was most probably caused by the severe hypokalemia despite central intravenous treatment (figure 2). Unfortunately, the $T$. Whipplei directed PCR was not performed and there was no possibility to do it on fixed tissue from duodenal biopsy. But the diagnosis of WD was certain based on clinical and histopathological proofs (figure 3).

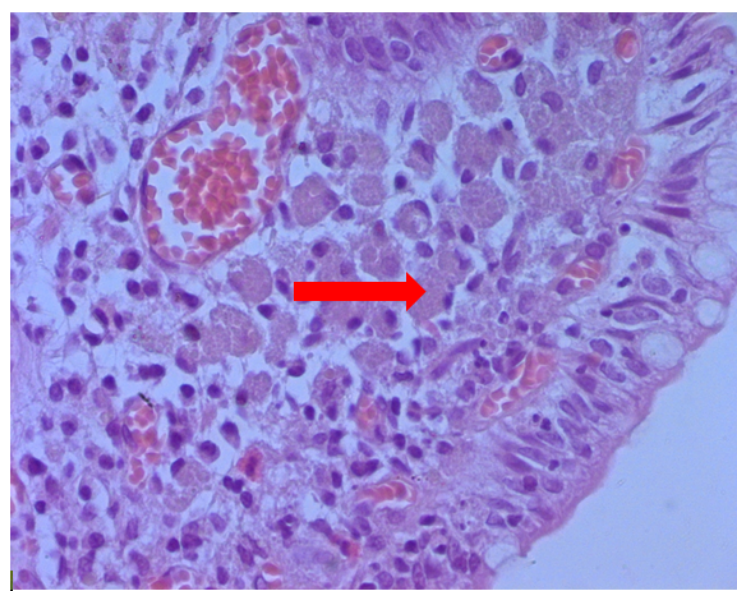

Figure 3: Many macrophages with finely grained cytoplasm are infiltrating the chorion of the duodenal mucosa (HE X 400).

\section{Discussion}

Diarrhea is common in transplant recipients. It is unpleasant and inconvenient for the patient, but severe diarrhea can lead to weight loss and dehydration, increased serum creatinine and fluctuating immunosuppressive drug levels. While the majority of cases of diarrhea are mild and transient, some are severe and prolonged, which can threaten graft survival [11]. In the DIDACT study that focused on severe and prolonged form of diarrhea in kidney transplant recipient, Maes et al found a positive microbiological examination of stools and got the diagnosis in only $22 \%$ of cases. The majority of infections were bacterial (17\%) including Campylobacter jejuni (11\%), Salmonella spp. (2\%) and Clostridium difficile (2\%). Treatment of infection resulted in remission in 17 of 22 patients [11]. Unlike our patient, whose stool bacterial examinations were negative for those common bacterial infections and both CMV antigenemia and search for Rotavirus were negative. In our case, as in the literature, the T.Whipplei remains a rare cause and usually a negative infectious investigation leads the physician to the immunosuppressive drugs gastrointestinal toxicity. Diarrhea is often reported as an adverse event in trials of immunosuppressive agents in transplant recipients [12,13].

It is unclear why some persons develop WD despite detection of this bacterium in the environment and as a frequent colonizer of the human gut, although innate defects in immunity or iatrogenic immunosuppression have been suggested as factors that may increase disease risk. It is also unclear if the patient was previously colonized with $T$. whipplei or if the donor may have played a role in transmission. In one hand, we don't perform automatically in the evaluation process of the recipient the search for T. whipplei in the stools, since it's not among the recommended work ups. In the other hand, the donor was a young thirty years old man in a good health that died after an accident. So in our case it seems impossible to define the certain origin of the disease.

In fact, studies have shown that the clinical course of Whipple's disease appears to be accelerated or exacerbated in individuals receiving immunosuppressive therapy $(9,14)$. Also, it is suggested that a defect in the cell-mediated immune system may play a role in the pathogenesis of this disease $[9,14,15]$.

Furthermore, arthritis is an early presenting symptom of WD, seronegative arthropathies cases may be untreated WD that blossom into the symptomatic phase of the disease under the effect of immunosuppression. That's why the literature evaluating immunosuppression as a risk factor for WD has been in the context of treatment for seronegative arthropathies [16,17]. Interestingly, development of disease in arthropathies is not limited to one class of immunosuppressive therapy and has been associated with corticosteroids, tumor necrosis factor inhibitors, calcineurin inhibitors, and antimetabolites [16,17].

But, WD is not frequent among solid organ recipients under immunosuppressive therapy because all patients are on routine prophylaxis for Pneumocystis jirovecii using TMP/SMX during the highest levels of immunosuppression in transplant patients. This antibiotic prophylaxis is likely protective against $T$. Whipplei. So, some explain the occurrence of WD with the fact that TMP/SMX is invariably stopped in kidney transplantation protocols as immunosuppression is tapered.

Like in our patient, it happens that when our patient complained of the first episode of febrile diarrhea five years after transplantation, he was on Sirolimus $2 \mathrm{mg}$ per day, mycophenolate mofetil (Cellcept 500 $\mathrm{mg}^{*} 3$ per day) and corticosteroids (prednisone $20 \mathrm{mg}$ per day) without antibiotic prophylaxis. But diarrhea is frequently observed when kidney transplant recipients are on the association of mycophenolate mofetil with Sirolimus.

Furthermore, before that episode, the patient received Imipenem as a treatment of urinary tract infections caused by pseudomonas aeruginosa. In the literature, the treatment with antibiotics such as carbapenem antibiotic family, as in the above case may also partially treat or provide prophylaxis against WD [7]. But no enough data are available to prove that a lifelong prophylaxis treatment of WD in renal recipients might be prudent, safe and avoid the relapses.

Our patient has also received ceftazidim and fosfomycin for his fourth urinary infection episode of a resistant pseudomonas aeruginosa. Unfortunately in the last three years (2012-2015), we decided to stop treating his urinary tract infections because we have concluded that it's rather colonization by the same resistant bacteria than an infection. That's why digestive symptoms in 2015 were more severe than those treated in 2012.

In addition to iatrogenic immunosuppressive therapy, genetic and immunological defects were described as factors contributing to WD risk. In-vitro cell assays suggest subtle defects in cellular immunity may lead to disturbed phagocytosis, intracellular degradation, and immunological clearance of $T$. whipplei [18]. It seems that there are: reduced or absent $T$. whipplei- specific Th1 response [19], abnormalities in T cells [20] and typically lower CD4/CD8 T-cell ratios [21], in infected cells by T. whipplei compared with controls.

As for the genetic factors, Martinetti et al has documented by a genetic analysis that there is an increased prevalence of human 
leukocyte antigen (HLA) DRB1 ${ }^{*} 13$ and DQB1 ${ }^{*} 06$ in WD [22]. In fact, our patient had not any of these predisposing HLA antigens.

In literature, other intertwined factors were proposed such as comorbid disease of the affected organ/graft may also play a role in developing WD [17]. Indeed, three cases were reported of WD as followed: Whipple's endocarditis in a porcine valve, Whipple's chorioretinitis associated to vitreitis in a kidney recipient [10] and Whipple's gastroenteritis in a liver transplant recipient. All of those cases have occurred in patients having an inflammatory state due to another process affecting the site of Whipple's manifestation. It is possible then that WD risk increases with disruption of innate immunological defenses, such as barrier function and mucosal immunity of the affected tissue by other infections or inflammatory processes [7]. In the liver recipient case, the WD was following liver transplantation with comorbid graft-versus-host disease (GVHD) both affecting the gastrointestinal tract (Table 1) [7].

\begin{tabular}{|c|c|c|c|c|c|}
\hline Case & 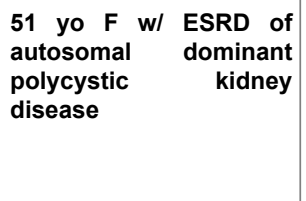 & $\begin{array}{l}76 \text { yo } M \text { w/ ESRD of } \\
\text { an unknown etiology }\end{array}$ & $\begin{array}{l}37 \text { yo } M \text { w/ ESRD of } \\
\text { an unknown etiology }\end{array}$ & $\begin{array}{l}66 \text { yo } M \text { wl } \\
\text { orthotopic } \\
\text { liver } \\
\text { transplant for cirrhosis and } \\
\text { carcinoma }\end{array}$ & $\begin{array}{l}27 \text { yo } M \text { wl } \\
\text { ESRD at age of } 15 \text { of } \\
\text { malformative uropathy and } \\
\text { lithiasis }\end{array}$ \\
\hline Graft type & Living donor kidney & Cadaveric kidney & Kidney & Cadaveric liver & Cadaveric kidney \\
\hline $\begin{array}{l}\text { Immunosuppressive } \\
\text { therapy }\end{array}$ & $\begin{array}{l}\text { Prednisone } 10 \mathrm{mg} \text {, } \\
\text { Azathioprine } 75 \mathrm{mg}\end{array}$ & $\begin{array}{l}\text { Prednisone } 5 \mathrm{mg} \text {, } \\
\text { Tacrolimus } 4 \mathrm{mg} \text {, MMF } \\
500\end{array}$ & $\begin{array}{l}\text { Prednisolone, } \\
\text { Tacrolimus } \\
\text { Azathioprine }\end{array}$ & $\begin{array}{l}\text { Rabbit-ATG } \\
\text { Prednisolone } \quad 1,5 \quad \mathrm{mg} / \mathrm{k} \\
\text { Tacrolimus }\end{array}$ & $\begin{array}{l}\text { Prednisolone } \\
\text { Neoral switched to Rapamune } \\
\text { MMF switched to Azathioprine }\end{array}$ \\
\hline Prophylaxis antibiotics & Doxycycline & TMP/SMX & Not reported & Dapsone & $\begin{array}{l}\text { TMP/SMX but no prophylaxis } \\
\text { one year after transplantation }\end{array}$ \\
\hline $\begin{array}{l}\text { Time between } \\
\text { transplantation/WD }\end{array}$ & 30 years & 1 year & 1 year & 3 months & $\begin{array}{l}13 \text { years (first diarrheal } \\
\text { symptoms appeared five } \\
\text { years after transplantation) }\end{array}$ \\
\hline Symptoms & $\begin{array}{l}\text { Blurry vision and visual } \\
\text { floaters. Three years } \\
\text { before: transient weight } \\
\text { loss, gastrointestinal } \\
\text { symptoms, migratory } \\
\text { polyarthritis. }\end{array}$ & $\begin{array}{l}\text { Heart failure, } \\
\text { arthralgia and loose } \\
\text { stools Fifteen years } \\
\text { before: Whipple's } \\
\text { disease of the hip } \\
\text { diagnosed. }\end{array}$ & $\begin{array}{l}\text { important diarrhea and } \\
\text { weight loss }\end{array}$ & diarrhea & $\begin{array}{l}\text { Diarrhea with malabsorption } \\
\text { syndrome, fever, arthralgia, } \\
\text { dehydration and severe } \\
\text { hypokalemia. }\end{array}$ \\
\hline Diagnosis & Chorioretinitis vitreitis & $\begin{array}{ll}\text { Porcine } & \text { Valve } \\
\text { Endocarditis } & \end{array}$ & Enteritis & Gastritis, enteritis, colitis & $\begin{array}{l}\text { Severe malabsorption } \\
\text { syndrome due to enteritis and } \\
\text { gastritis. }\end{array}$ \\
\hline Endoscopy & Not reported & $\begin{array}{l}\text { EGD negative } 2 \text { years } \\
\text { before transplant }\end{array}$ & EGD negative & 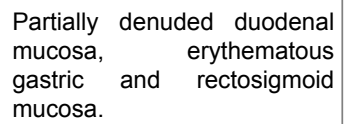 & $\begin{array}{l}\text { Hiatus hernia, erythematous } \\
\text { antral mucosa, severe } \\
\text { gastritis and duodenal } \\
\text { lymphangiectasia }\end{array}$ \\
\hline histology & $\begin{array}{l}\text { Gram positive organism } \\
\text { in histiocytes of vitreous } \\
\text { fluid }\end{array}$ & $\begin{array}{l}\text { Negative organisms } \\
\text { by Gram stain }\end{array}$ & $\begin{array}{lr}\text { Duodenal } & \text { biopsies } \\
\text { PAS-positiver } & \text { with } \\
\text { foamy macrophages }\end{array}$ & $\begin{array}{l}\text { Gastric, duodenal and colonic } \\
\text { biopsies PAS-positive with } \\
\text { foamy macrophages }\end{array}$ & $\begin{array}{l}\text { Gastric and duodenal } \\
\text { biopsies PAS-positive with } \\
\text { foamy } \\
\text { Atrophied villi, and abraded } \\
\text { epithelium. }\end{array}$ \\
\hline $\begin{array}{l}\text { Diagnosis biology } \\
\text { confirmation }\end{array}$ & $\begin{array}{l}\text { Positive for Tropheryma } \\
\text { whipplei by directed PCR }\end{array}$ & $\begin{array}{l}\text { Positive for } \\
\text { Tropheryma whipplei } \\
\text { by directed PCR }\end{array}$ & $\begin{array}{l}\text { ZN and modified ZN } \\
\text { stain negative } \\
\text { No PCR confirmation }\end{array}$ & $\begin{array}{l}\text { directed PCR: negative } \\
\text { FISH: positive }\end{array}$ & $\begin{array}{l}\text { No directed PCR } \\
\text { Performed (patient dead } \\
\text { before histological diagnosis) }\end{array}$ \\
\hline Reference & [9] & [25] & {$[26]$} & {$[16]$} & Current case \\
\hline
\end{tabular}

Table 1: characteristics of all the reported cases of WD after solid organ transplantation.

In reviews, clinical manifestation caused by $\mathrm{T}$. whipplei is characterized by two phases with an average interval of 6 years. The prodromal stage is marked by chronic non-specific findings: fever, myalgia, arthralgia and arthritis. In the later steady-state phase, gastrointestinal symptoms like diarrhea and malabsorption are typically seen, although other organs can be involved. About $15 \%$ of patients do not present these classical signs witch can provide a high index of suspicion in order to establish the diagnosis. The ocular and renal manifestations occur rarely [6,10]. The renal involvement has occasionally been described, cases of AA amyloidosis [23], Ig A nephropathy [24,25], granulomatous chronic interstitial nephritis $[27,28]$.

In our patient, the first episode occurred five years after transplantation and introduction of double immunosuppression and corticosteroids. First, the prodromal phase was intertwined with urinary infectious complications of the graft. So the non-specific signs 
like fever and myalgia without arthralgia nor arthritis couldn't be attributed to WD. Second, the diagnosis was delayed (thirteen years) because of the interposition of the gastrointestinal manifestation of MMF digestive intolerance (vanished after switching it to Azathioprine (Imurel)) and digestive manifestation of WD. Perhaps the interposition of the urinary tract infections antibiotics treatment has also basterdized the T.whipplei infection and hided the real origin of diarrhea and fever.

As a reflection of the role of exposure to fecal matter in the environment, it's described that other infections, including giardiasis and cryptosporidiosis, have been found to co-associate with gastrointestinal WD [29]. But, whether co-infections or comorbid inflammatory conditions contribute to the development of WD or simply co-associate remains unclear.

Nevertheless, the intriguing possibility is raised that WD may be present in and fuel inflammatory conditions, especially gastrointestinal conditions that are often refractory to immunosuppressive therapy [30].

The positive PAS staining on duodenal biopsies is often considered pathognomonic for WD. But, PAS staining is not specific as Mycobacterium avium-intracellulare complex, Rhodococcus equi, and rarely Histoplasma species can have a similar histologic appearance. That's why in our case, we performed additional stains (acid-fast to rule out M. avium-intracellulare complex and Rhodococcus, and silver stain to rule out yeast) and these other organisms were not detected [26].

In literature, the diagnosis of WD was not entertained until after the gastrointestinal tract biopsies had been fixed. While the sensitivity of PCR for T. whipplei has been reported to be $96-100 \%$ on fresh tissue $[31,32]$, PCR often fails to amplify on fixed tissue, owing to formalininduced DNA cross- linking that interferes with amplification [33]. That's why in our case, the PCR was not performed after the patient was dead. The PCR on fixed tissue, which we dispose from duodenal biopsy performed two days before his death, wouldn't be conclusive. So our diagnosis was retrospective and remained based on histological arguments.

\section{Conclusion}

In conclusion, this case shows that the etiology of severe diarrhea following transplantation is complex. As diarrhea is generally less life threatening than the loss of a graft, it is suggested that the management of diarrhea should be restrained until it becomes severe and prolonged. But in severe forms, an etiology should be sought so that appropriate treatment can be given and serious complications or death can be avoided. After stopping the diarrhea-causing drugs and changing in diet and lifestyle, the rare causes such as WD have to be kept in mind. So, empiric antibiotic treatments aiming T.whipplei in addition to other common bacteria should be considered before any changes in immunosuppression.

\section{References}

1. Dutly F, Altwegg M (2001) Whipple's disease and "Tropheryma whippelii". Clin Microbiol Rev 14: 561-583.

2. Bai JC, Mazure RM, Vazquez H, Niveloni SI, Smecuol E, et al. (2004) Whipple's disease. Clin Gastroenterol Hepatol 2: 849-860.

3. Raoult D, Birg ML, La Scola B, Fournier PE, Enea M, et al. (2000) Cultivation of the bacillus of Whipple's disease. N Engl J Med 342: 620-625.
4. Fenollar F, Puéchal X, Raoult D (2007) Whipple's disease. N Engl J Med 356: 55-66.

5. Marth T (2015) Tropheryma whipplei, Immunosuppression and Whipple's disease: from a low- pathogenic, environmental infectious organism to a rare, multifaceted inflammatory complex. Dig Dis 33: 190-199.

6. Famularo G, Minisola G, De Simone C (2005) A patient with cerebral Whipple's disease and a stroke-like syndrome. Scand J Gastroenterol 40: 607-609.

7. Vindigni SM, Taylor J, Quilter LA, Hyun TS, Liu C, et al. (2016) Tropheryma whipplei infection (Whipple's disease) in a patient after liver transplantation. Transpl Infect Dis 18: 617-624.

8. Rocha S, Lobato L, Carvalho MJ, Malheiro J, Vizcaíno R, et al. (2011) Renal transplantation in AA amyloidosis associated with Whipple's disease. Amyloid 18: 240-244.

9. Kneitz C, Suerbaum S, Beer M, Müller J, Jahns R, et al. (2005) Exacerbation of Whipple's disease associated with infliximab treatment. Scand J Rheumatol 34: 148-151.

10. Razonable (2008) Ocular Whipple's disease after transplantation. Transplant Infectious Disease.

11. Maes B, Hadaya K, de Moor B, Cambier P, Peeters P, et al. (2006) Severe diarrhea in renal transplant patients: results of the DIDACT study. Am J Transplant 6: 1466-1472.

12. Sollinger HW (1995) Mycophenolate mofetil for the prevention of acute rejection in primary cadaveric renal allograft recipients. Transplantation 60: $225-232$.

13. Kahan BD (2000) Efficacy of sirolimus compared with azathioprine for reduction of acute renal allograft rejection: A randomised multicentre study. Lancet 356: 194-202.

14. Mahnel R, Kalt A, Ring S, Stallmach A, Strober W, et al. (2005) Immunosuppressive therapy in Whipple's disease patients is associated with the appearance of gastrointestinal manifestations. Am J Gastroenterol 100: 1167-1173.

15. Desnues B, Ihrig M, Raoult D, Mege JL (2006) Whipple's disease: a macrophage disease. Clin Vaccine Immunol 13: 170-178.

16. Mahnel R, Kalt A, Ring S, Stallmach A, Strober W, et al. (2005) Immunosuppressive therapy in Whipple's disease patients is associated with the appearance of gastrointestinal manifestations. Am J Gastroenterol 100: 1167-1173.

17. Marth T (2015) Systematic review: Whipple's disease (Tropheryma whipplei infection) and its unmasking by tumour necrosis factor inhibitors. Aliment Pharmacol Ther 41: 709-724.

18. Marth T (2009) New insights into Whipple's disease - a rare intestinal inflammatory disorder. Dig Dis 27: 494-501.

19. Moos V, Kunkel D, Marth T, Feurle GE, LaScola B, et al. (2006) Reduced peripheral and mucosal Tropheryma whipplei-specific Th1 response in patients with Whipple's disease. J Immunol 177: 2015-2022.

20. Marth T, Roux M, von Herbay A, Meuer SC, Feurle GE (1994) Persistent reduction of complement receptor 3 alpha-chain expressing mononuclear blood cells and transient inhibitory serum factors in Whipple's disease. Clin Immunol Immunopathol 72: 217-226.

21. Schinnerling K, Moos V, Geelhaar A, Allers K, Loddenkemper C, et al. (2011) Regulatory T cells in patients with Whipple's disease. J Immunol 187: 4061-4067.

22. Martinetti M, Biagi F, Badulli C, Feurle GE, Müller C, et al. (2009) The HLA alleles DRB $1^{\star} 13$ and DQB $1^{\star} 06$ are associated to Whipple's disease. Gastroenterology 136: 2289-2294.

23. Biernat S, Kozlowski W (1975) [Case of Whipple's disease complicated by amyloidosis]. Pol Tyg Lek 30: 113-114.

24. Stoll T, Keusch G, Jost R, Burger H, Oelz O (1993) IgA nephropathy and hypercalcemia in Whipple's disease. Nephron 63: 222-225.

25. Evrenkaya R, Basak M, Cosansel S, Cankir Z, Guney Y, et al. (1999) A case of Whipple's disease associated with acute Ebstein Barr virus hepatitis and Berger's disease. Nephrol Dial Transplant 14: 241-242. 
Citation: Abdellaoui I, Sahtout W, Mansour IB, Mokni M, Azzabi A, et al. (2016) Malabsorption Syndrome Due to Tropheryma Whipplei Severe Infection in a Patient Thirteen Years after Kidney Transplantation. J Nephrol Ther 6: 272. doi:10.4172/2161-0959.1000272

Page 6 of 6

26. Hamrock D, Azmi FH, O'Donnell E, Gunning WT, Philips ER, et al. (1999) Infection by Rhodococcus equi in a patient with AIDS: histological appearance mimicking Whipple's disease and Mycobacterium avium-intracellulare infection. J Clin Pathol 52: 68-71.

27. Schlumpf A, Marbet UA, Stöcklin E, Wegmann W, Lämmle B, et al (1983) Chronic interstitial nephritis in Whipple's disease. Klin Wochenschr 61: 25-33.

28. Marie I, Lecomte F, Levesque H (2000) Granulomatous nephritis as the first manifestation of Whipple disease. Ann Intern Med 132: 94-95.

29. Meier-Willersen HJ, Maiwald M, von Herbay A (1993) [Whipple's disease associated with opportunistic infections]. Dtsch Med Wochenschr 118: 854-860.
30. Kattan JN, Rehm SJ, van Duin D, Pettersson G, Rodriguez ER, et al. (2013) Whipple's disease: a case revisited 14 years after diagnosis. Infec Dis Clin Pract 21: 201-203.

31. Müller SA, Vogt P, Altwegg M, Seebach JD (2005) Deadly carousel or difficult interpretation of new diagnostic tools for Whipple's disease: case report and review of the literature. Infection 33: 39-42.

32. von Herbay A, Ditton HJ, Maiwald M (1996) Diagnostic application of a polymerase chain reaction assay for the Whipple's disease bacterium to intestinal biopsies. Gastroenterology 110: 1735-1743.

33. Alaibac M, Filotico R, Giannella C, Paradiso A, Labriola A, et al. (1997) The effect of fixation type on DNA extracted from paraffin-embedded tissue for PCR studies in dermatopathology. Dermatology 195: 105-107. 